\title{
La construcción del significado en la experiencia estética
}

\author{
Óscar del Castillo Sánchez \\ Alumno de doctorado. Facultad de Filosofía. Universidad \\ Nacional de Educación a Distancia (UNED). \\ oscar.delcastillo@yahoo.co.uk \\ DOI: http://doi.org/10.15366/bp2019.22.018 \\ Bajo Palabra. II Época. No 22. Pgs: 347-362
}

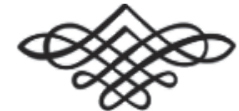


Recibido: 12/12/2017

Aprobado: 02/10/2019

\section{Resumen}

A partir de las propuestas teóricas de Roman Ingarden y Wolfgang Iser en el terreno de la crítica literaria, en este artículo se plantea que el vacío es constitutivo de toda obra de arte, y que cabe considerar esta, en sus distintas modalidades posibles, como un mixto de indeterminación y de significado explícito. Esto permite definir un mecanismo común de formación del significado actuante en las diversas formas artísticas

Palabras clave: Significado, fenomenologia, arte, abstracción, estética.

\section{Abstract}

Based on the theoretical proposals of Roman Ingarden and Wolfgang Iser in the field of literary criticism, this article states that the void is constitutive of every work of art, and therefore it is possible to consider the work of art, in its different possible forms, as a mixture of indetermination and explicit meaning. This allows to define a common mechanism of meaning formation that acts in the different artistic forms.

Keywords: Meaning, Phenomenology, Art, Abstraction, Aesthetics. 


\section{Introducción}

YA EN LA ANTIGÜEDAD GRIEGA se planteó el problema del significado de la música, es decir, la pregunta por el modo en que una forma artística no imitativa hace referencia a algo externo a sí, como ocurre incluso en el caso de la música absoluta. La cuestión atañe asimismo a la pintura y a la escultura abstractas, en las cuales, pese a la ausencia de toda voluntad figurativa, las formas remiten siempre, de algún modo, a significados externos. Esto sugiere la posibilidad de que en las diversas artes actúen unos mecanismos básicos de significación similares, en virtud de lo cual sería posible enunciar un modelo de constitución del significado y del sentido de la obra de arte valedero para las distintas modalidades artísticas, aunque sin perder de vista las importantes diferencias entre ellas. Este trabajo se propone esbozar un modelo de ese tipo.

Esta tesis se complementa con la idea de que los procesos de constitución del significado encontrados en las artes no figurativas operan de modo similar en obras de intención mimética, puesto que incluso la mímesis comporta un grado de abstracción $-y$, por ende, de indeterminación- ineliminable. En última instancia, el mero hecho de proponerse un objeto para una contemplación estética desencadenaría este tipo de fenómenos de significación con independencia de las propiedades formales del objeto, como muestran los ready made. Por tanto, dentro de una misma modalidad artística cabe encontrar una gama continua de casos entre el polo del mayor realismo y el de la abstracción más completa, en todos los cuales actuarían procesos de construcción del sentido comparables. Algo de lo que el modelo aquí propuesto pretende también dar razón.

\section{El concepto de indeterminación en la obra de arte}

Para el estudio de este continuo entre los polos de la mímesis y de la abstracción, se acudirá a dos propuestas teóricas planteadas en el campo de la crítica literaria. La primera, formulada por Roman Ingarden en una serie de trabajos acerca de la obra de literatura ${ }^{1}$, se basa en la idea central de lugar de indeterminación. Para

\footnotetext{
${ }^{1}$ Puede encontrarse una buena síntesis de los principios aquí referidos de la teoría literaria del pensador polaco en Ingarden, R., "Concreción y reconstrucción". En Warning, Rainer (ed.), Estética de la recepción. Madrid: La Balsa de Medusa, 1989, pp. 35-53.
} 
Ingarden, la experiencia de la obra exige del lector una actividad creativa que concretice lo narrado por el texto; en especial, que le otorgue en la imaginación aquellas cualidades sensibles que no pueden representarse en un discurso verbal y lineal ${ }^{2}$. Se espera del lector, pues, que defina aquello que permanece necesariamente indeterminado en la obra. Todo lector conoce este aspecto de la actividad lectora, la cual no se reduce a una comprensión de lo literalmente expresado en el texto, sino que va acompañada de una producción de imágenes que de alguna manera encarnan mentalmente lo narrado.

Ingarden compara este proceso con el que tiene lugar cuando se interpreta una obra musical a partir de una partitura. Esta sólo contiene las indicaciones necesarias para recrear la obra, lo cual exige del intérprete un verdadero acto creativo que acontece en el espesor que media entre la notación y la ejecución particular, auténtico espacio de libertad para la actividad del ejecutante. Según este paralelo, la obra literaria contendría también las indicaciones que permiten constituir lo que denominaremos aquí su objeto imaginario o inmanente, una constitución que requiere del lector, como la interpretación musical, de una tarea creativa. Pues, como se ha afirmado desde distintos planteamientos teóricos, la obra de arte no existiría por sí sola, sino que sus virtualidades sólo se ven actualizadas al constituirse su objeto imaginario correlativo a través de la actividad del receptor.

$\mathrm{Si}$, como se ha señalado antes, distintas obras presentan grados diversos de concreción, algunas proporcionarán descripciones minuciosas de su objeto, mientras que otras sólo darán las claves imprescindibles para su comprensión. Pero entre estos dos extremos no habría sino una diferencia de grado en lo que se refiere a los procesos a de constitución del sentido y de los significados de la obra, procesos que participarán siempre de la resolución de las indeterminaciones de la obra por parte del receptor.

Para Wolfgang Iser, el lugar de indeterminación toma un sentido más radical que en Ingarden, pues para este autor el vacío o negatividad de la obra cumpliría un papel central en la formación del sentido, más allá de una mera "ilustración" del contenido expreso. En El acto de leer ${ }^{3}$, se propone que el texto estaría compuesto de bloques o segmentos más o menos autónomos, cada uno de los cuales integraría una unidad de significado inteligible. Dada la relativa autonomía de estos bloques, aparecen entre ellos discontinuidades o vacíos de significado que

\footnotetext{
2 Wolfgang Iser, en su crítica a la idea de lugar de indeterminación en Ingarden, hace hincapié en las limitaciones de este planteamiento: "podría suceder [...] que con la implementación de los espacios de indeterminación Ingarden sólo piense realmente en la producción de una ilusión de percepción" (cf. Iser, Wolfgang, El acto de leer. Teoría del efecto estético, Madrid, Taurus, 1987, p. 273).

3 Ibíd., pp. 280ss.
} 
el lector debe llenar activamente para restituir la continuidad y, por ende, la trabazón del conjunto de la trama y la unidad del objeto imaginario de la obra ${ }^{4}$. Dado que el relato puede ser discontinuo o unitario en mayor o menor medida, este planteamiento implica la existencia de una gama continua entre unidad y fragmentación en la que se situaría toda obra. Esta idea puede extenderse a la recepción de otras formas artísticas: así ocurre en las artes plásticas -figurativas o no-, en la música o en la arquitectura, como se referirá en detalle más adelante. Por tanto, cabe esperar que, como en el caso de la literatura, toda obra de arte, en virtud de su naturaleza mixta de significado y negatividad, se situará siempre en algún lugar entre el polo de una indeterminación completa y el de un significado unívoco -extremos ambos que nunca se alcanzan en la realidad artística. Nuestra propuesta de un modelo de formación del significado artístico se fundamentará en estas dos ideas: por un lado, la construcción del objeto inmanente/sentido de la obra a partir de fragmentos de significado, y, por otro, el continuo entre figuración y vacío.

\section{La relación entre indeterminación y significado}

LA HISTORIA DE LAS ARTES BRINDA profusos ejemplos de distintas dosificaciones de significado inteligible y de negatividad en la obra. De hecho, puede considerarse que esa dosificación es correlativa con la evolución o deriva artística, y que sólo en la modernidad se dan al mismo tiempo obras, estilos o tendencias con grados de concreción/indeterminación diversos. Así, si en la antigüedad grecorromana la obra se concibe como objeto de una lectura unívoca ${ }^{5}$, y por lo tanto plenamente determinada, con el auge del cristianismo surge la necesidad de la alegoría:

Dado que, para la poesía cristiana, la verdad de lo representable residía en las tres esferas de lo invisible $[\ldots]$ necesitaba del discurso alegórico (o tipológico) para mantener siempre abierta la diferencia en la correspondencia entre figura (o acontecimiento) y significación. Esta diferencia entre figura y significación implicaba, para el destinatario, una invitación a imaginar algo más que lo dicho [énfasis mío] ${ }^{6}$.

\footnotetext{
${ }^{4}$ Nótese que estas discontinuidades aparecen incluso entre oraciones contiguas, entre las cuales se produce inevitablemente un hiato en el significado que el lector debe solventar.

5 Para Hegel, así ocurre en la escultura clásica, plena encarnación de la Idea, en que forma y contenido alcanzan la unidad más perfecta. Esta forma de belleza requiere de una comunidad de receptores culturalmente unitaria, de modo que la univocidad/determinación de la experiencia de la obra resulta, por un lado, de esa unidad entre forma y contenido y, por otro, de la cohesión del grupo humano que la produce y recibe.

${ }^{6}$ Jauss, Hans-Robert, Experiencia estética y hermenéutica literaria. Ensayos en el campo de la experiencia estética, Madrid, Taurus, 1986, pp. 127-128.
} 
Este alegorismo no debe entenderse al modo posmoderno, en cuanto ilimitada dinámica de remisión entre significantes, pues la exégesis de este tipo de textos discurría por cauces bien restringidos ${ }^{7}$. Pero la posibilidad de interpretar la obra de modos diversos, aunque predeterminados, supone ya un cambio cualitativo con respecto del univocismo clásico. Será en el Barroco cuando se introduzca la discontinuidad como recurso artístico bajo la forma de suspensión, algo que puede detectarse en las distintas artes de la época, desde el teatro hasta la arquitectura, desde la música hasta la pintura. Así, frente a la fidelidad a lo real que caracteriza su obra temprana, en el Velázquez maduro:

La superficie de las cosas [...] se convierte en una sucesión de toques rápidos, vibrantes y desunidos que, vistos de lejos, se integran en una admirable unidad visual [...] esa capacidad de reconstruir en la retina del espectador la realidad, taquigráficamente representada por medio de toques sueltos y deshechos ${ }^{8}$.

Pese a ello, en el Barroco la interpretación del objeto sigue dependiendo de cánones predefinidos: la arquitectura se atiene aún a un vocabulario procedente de la antigüedad latina, aunque deformado y utilizado a voluntad; la poesía de Góngora o Quevedo se apoya de continuo en referencias mitológicas. En obras como las Pasiones de J. S. Bach, "cada situación emocional, cada personaje, cada frase y hasta cada palabra [bíblicas] de cierto relieve encuentran su exacta y pertinaz correspondencia en el lenguaje de los sonidos" ", de manera que las secuencias sonoras forman prácticamente un léxico que "en parte son invenciones originales, en parte revelan 'asociaciones de ideas universalmente admitidas tanto en Alemania como en Francia y en Italia"' ${ }^{10}$. El estadio barroco ocuparía por tanto un lugar intermedio entre la univocidad de lo clásico y la abstracción contemporánea, en que el vacío/ suspensión constituye un recurso estético importante, aunque la obra se apoya aún en códigos compartidos que guían la formación del objeto inmanente y de su significado.

Tras el Neoclasicismo, las distintas artes se alejan progresivamente del ideal figurativo, lo que culminaría en la abstracción de las vanguardias históricas. Esto, que a primera vista puede parecer un cambio radical en las relaciones entre forma y significación, en el marco de la polaridad definida se entiende como un importante aumento del vacío de la obra con respecto al significado, sin que ello cambie en esencia el mecanismo constitutivo del objeto imaginario con respecto del actuante

\footnotetext{
$\overline{7}$ Véase la lectura que hace Jauss de un texto medieval; cf. Ibíd, op. cit., pp. 128ss.

8 Pérez, Alfonso E., Pintura barroca en España (1600-1750), Madrid, Cátedra, 1992, p. 220.

9 Fubini, Enrico, Música y lenguaje en la estética contemporánea, Madrid, Alianza, 2006, p. 67.

${ }_{10}$ Ídem.
} 
en la obra figurativa. Este abandono paulatino de la mímesis acaece en las distintas artes más o menos al mismo tiempo: pintura y escultura desisten de su tradicional misión representativa; en arquitectura, el lenguaje abstracto desplaza a los estilos históricos; en música, se abandona primero la tonalidad y, después, toda estructura sonora reconocible. La poesía reniega, como la pintura, del ideal figurativo.

Puede entonces considerarse que la diferencia entre abstracción y mímesis, en lo que atañe al significado, radica en que en la primera domina la negatividad sobre los significados inteligibles, mientras que en la segunda imperan estos sobre aquella. En las obras más abstractas, el receptor ha de asumir la tarea de restituir la continuidad entre porciones de significado dispersos en medio de un vacío dominante, y de generar una lectura apoyada en tales porciones. En relación con el poema contemporáneo, observa Rosa Navarro que:

No hay código alguno literario que permita ahondar en el texto, muy pocas son las referencias a una tradición literaria [...] La denotación exacta escapa a menudo al lector por falta de precisiones, pero este no pierde la aguja de navegar si sabe empaparse de las palabras. Podrá no entender, pero sabrá qué dice o qué sentimiento trasmina el poema ${ }^{11}$.

En estas obras, el significado no se construye como en un texto que pretenda transmitir un mensaje literal y sin ambigüedades, sino que emerge de la confluencia entre las sugerencias de las palabras y las construcciones empleadas, sus connotaciones, su musicalidad, las estructuras rítmicas y sonoras del poema, y de la interacción de todos estos componentes, que forman a modo de retazos de un significado enormemente indefinido y ambiguo, que sólo se perfila en algún grado en esa interacción y a través de la actividad del lector empeñado en desentrañar, o más bien construir, su sentido. Un sentido que, una vez vislumbrado, antes que directamente aprehendido, no puede traducirse en conceptos, sino que permanece como la intuición del mundo que la obra encarna.

Este modo de formación del sentido en la poesía guarda una gran afinidad con lo que acontece en la escucha de la pieza musical. En la música absoluta, como en el poema contemporáneo, domina el vacío, y el significado de la obra sólo puede constituirse a partir de los fragmentos significativos aportados por el sonido, lo que incluye la hechura formal de la pieza -ya se trate de una fuga, una sonata, o una obra aleatoria- o el simbolismo del sonido aislado o de los grupos de sonidos y las relaciones entre ellos. Para Eero Tarasti, la música es siempre una dialéctica entre un fenómeno sonoro presente y unas estructuras mentales o espirituales virtuales, como pueden ser los principios de la cognición, de la significación, o de la estética.

11 Navarro, Rosa, Cómo leer un poema, Barcelona, Ariel, 1998, pp. 112-113. 
La música de Eric Satie, por ejemplo, parece basarse en el principio de un significado ausente que incita al que escucha a crear las significaciones en su imaginación ${ }^{12}$.

Algo semejante ocurre ante la obra de pintura abstracta, que a menudo se plantea de manera explícita como una especie de música visual. Wassily Kandinsky, por ejemplo, se apoyó con frecuencia en conceptos y metáforas musicales en su teoría de la pintura ${ }^{13}$. Para este autor, el cuadro abstracto constituye una especie de campo de tensiones y de equilibrios dinámicos visuales sin referencia figurativa alguna, y su lectura consiste en la actividad comprensiva de estos juegos visuales, cuyo sentido emerge, como en el poema o en la música, en el esfuerzo del sujeto por aprehender las interacciones de los distintos componentes pictóricos, y en la confrontación de estas aprehensiones con el horizonte inmanente y personal desde el que se recibe la obra.

Sin embargo, el proceso de abstracción no se detiene en el abandono de la mímesis, sino que sólo se completa al desaparecer la forma misma. Así ocurre en el minimalismo en pintura y escultura, o en obras como 4' 33" de John Cage. Este camino desemboca, en última instancia, en el abandono de la actividad artística, como hizo de hecho Jorge Oteiza en los años 50 del siglo pasado ${ }^{14}$. El arte del vacío no proporciona ya elemento significativo alguno, sino que la mera ausencia suscita la vuelta de la mirada hacia la interioridad propia. La obra ofrece un paréntesis, un campo de silencio en medio del estruendo de la cultura mediática actual, en que, a falta de estímulos externos, el sujeto se recoge en sí mismo: el polo objetual queda reducido al mínimo posible, y el papel activo del receptor alcanza el máximo.

\section{La construcción del significado}

DADO QUE, DE ACUERDO CON LO ANTERIOR, no habría una diferencia radical entre la obra más realista y la más abstracta en lo que se refiere a la construcción del significado, sino que ambas ocuparían las posiciones extremas de un continuo, si se consigue formular un modelo que dé razón del modo en que se resuelven las indeterminaciones de la obra, tal modelo permitirá comprender estos procesos no sólo en la dimensión longitudinal de los diversos grados de abstracción dentro de una misma actividad artística, sino también en la dirección transversal entre las

${ }_{12}$ Cf. Tarasti, Eero, Sémiotique musicale Limoges, PULIM, 1996, p. 388.

${ }^{13}$ Cf. Kandinsky, Wassily, Punto y línea sobre el plano. Contribución al análisis de los elementos pictóricos, Barcelona, Labor, 1991.

${ }^{14}$ Cf. Oteiza, J., "El final del arte contemporáneo". En Oteiza. Propósito experimental. Madrid, Fundación Caja de Pensiones, 1988, p. 230 
distintas artes. Como se ha apuntado más arriba, el modelo propuesto parte de la idea de objeto inmanente o sistema noemático de la obra ${ }^{15}$, que puede definirse como la construcción mental que el sujeto elabora activamente a partir de la materia sensible proporcionada por el objeto estético. Para Aron Gurwitsch, el noema perceptivo "es la cosa material percibida desde cierto punto de vista, según un aspecto determinado, de acuerdo con una cierta orientación con respecto al sujeto de la percepción" ${ }^{16}$, mientras que un sistema noemático -u objeto inmanente, imaginario o intencional, en la terminología del primer Husserl- consistiría en "la concatenación sistemáticamente organizada de noemas" ${ }^{17}$, o, a grandes rasgos, en aquel objeto mental unitario resultante de la integración estructurada de los sucesivos aspectos parciales que el objeto real presenta. Este objeto inmanente recoge e integra todo lo relativo a la experiencia de la obra:

En la descripción de un noema perceptivo particular, debemos incluir todas las cualidades, las propiedades y los atributos de la cosa percibida que jueguen algún papel en la percepción individual de que se trate, ya sea que la propiedad en cuestión se dé en la experiencia sensible directa o que sólo haya en ésta una mera referencia a ella ${ }^{18}$.

Aquí se considera una noción de objeto intencional en que la estructura noemática abarcaría no sólo los aspectos puramente perceptivos o formales del objeto, sino que incluiría también los afectos desencadenados por su percepción, o las asociaciones e imágenes de todo tipo suscitadas en el curso de su experiencia, desde las más privadas a las más ampliamente compartidas por la comunidad. Si atendemos, por ejemplo, a lo afirmado desde la psicología de la música, cabe incluir en el objeto inmanente incluso las reacciones fisiológicas desencadenadas en la escucha de la obra ${ }^{19}$, reacciones que, en su conjunción con los demás aspectos de la vivencia musical -o estética, en general- se tornarían significativas. Todos estos aspectos constituyen una unidad múltiple y sintética, una duración en sentido bergsoniano, en que sus componentes se ven mutuamente connotados a través de relaciones complejas y múltiples, y a cuyos elementos y relaciones, indiscernibles en esa unidad, sólo puede accederse por medio de un análisis retrospectivo.

${ }_{15}$ A los efectos de esta discusión, las nociones de objeto inmanente y de sistema noemático, ambas de raíz husserliana, se entienden como básicamente equivalentes. En rigor, subsisten diferencias importantes entre ambos conceptos, pues el primero pertenece a una concepción dualista de la relación objetual, mientras que con el segundo se pretende haber superado ese dualismo. Esta cuestión no afecta significativamente a nuestro argumento.

${ }_{16}$ Gurwitsch, Aron, El campo de la conciencia. Un análisis fenomenológico, Madrid, Alianza, 1979, p. 204

${ }_{17}$ Ibid., op. cit., p. 260.

18 Ibid., op. cit., p. 204.

19 Juslin, P., "Emotional Responses to Music". En Hallam, Susan, Cross, Ian, y Thaut, Michael (eds.), Oxford Handbook of Music Psychology. Oxford: Oxford University Press, 2012, pp. 136-138. 
Como señalan tanto Husserl como Gurwitsch, objeto intencional / sistema noemático equivale a significado en sentido lato: "Husserl define el noema perceptivo en cuanto sentido, significación o significado de la percepción" ${ }^{20}$, de manera que esa multiplicidad de materiales de todo tipo -conceptuales, sensibles, afectivos-, evocada y constituida en unidad sintética en el proceso de aprehensión el objeto, conforma el significado y el sentido de la obra.

El objeto inmanente no se concibe en un ámbito vacío, sino que, por el contrario, es engendrado en el seno de lo que la fenomenología denomina horizonte interno ${ }^{21}$. Este horizonte puede definirse como un sustrato de sedimentos previos del cual ese objeto toma tanto su forma organizativa básica como aquellos contenidos que, ausentes del objeto real percibido, aparecen sin embargo en la conciencia del sujeto receptor en el acto de percepción. Si relacionamos esto con la idea antes apuntada de resolución de las indeterminaciones de la obra, vemos que estas se solventan con materiales -tanto estructuras básicas como contenidos concretosprocedentes de este sustrato.

El horizonte intencional se compone de elementos heterogéneos, tales como unidades culturales intersubjetivamente compartidas, la experiencia previa de otras obras de arte, o de componentes individuales, como los generados por la actividad imaginativa del receptor. Aquí se considerará que estos contenidos se organizan en forma de red semántica con una topología rizomática. En esa red o plexo, los elementos y esquemas componentes forman unidades semióticas o culturales más o menos definidas, vinculadas unas a otras mediante enlaces de intensidad diversa, susceptibles de crearse o de disolverse a cada momento. El conjunto de estas unidades y de sus relaciones forman una unidad sintética o multiplicidad bergsoniana que constituye, en última instancia, el universo mental del individuo. Este puede entenderse como organizado según una estructura reticular en que unos contenidos aparecen vinculados a otros dentro de una semiosfera privada. Este horizonte, según se ha señalado, albergaría tanto materiales procedentes de la comunidad de pertenencia, intersubjetivamente compartidos ${ }^{22}$, como contenidos elaborados en el curso de vivencias y reflexiones privadas, con todos los mixtos posibles entre ambos.

Por su parte, el objeto intencional de la obra, constituido en el seno del horizonte interno en el curso de la experiencia estética, consistiría, al igual que ese horizonte, en una unidad sintética bergsoniana, en una multiplicidad de contenidos heterogéneos enlazados entre sí en rizoma, de manera que su constitución puede

${ }^{20}$ Gurwitsch, A., El campo de la conciencia, op. cit., p. 206.

${ }^{21}$ Cf. Ibid., pp. 279ss.

22 Esto es lo que, de acuerdo con H. R. Jauss, constituiría el horizonte entornal de recepción de la obra para una comunidad y un momento dados. Cf. Jauss, H. R., Experiencia estética y hermenéutica literaria, op. cit., p. 17. 
entenderse, desde nuestro modelo, como el proceso de formación de un plexo, de estructura isomorfa a la del horizonte en que se constituye, e integrado por contenidos interrelacionados que procederían de la percepción sensible de la obra, del propio horizonte desde el que esta se recibe o de las reflexiones que la experiencia de la obra suscite, todo ello en interacción dinámica. La incorporación de material nuevo, derivado, por ejemplo, de la percepción de nuevos aspectos de la obra, desencadena nuevas síntesis y reorganizaciones del conjunto de la estructura noemática, que nunca es meramente aditiva.

Pueden distinguirse dos mecanismos operantes en la experiencia de la obra, mecanismos que aquí denominaremos de recepción simbólica y de recepción dialéctica. Aunque en el instante inicial del encuentro con la obra domina el primer modo, en fases ulteriores ambos se alternan y entrelazan en la experiencia del objeto. La recepción simbólica consistiría en un aprehender inmediato e intuitivo, prerreflexivo, en que se captan los aspectos sensibles más destacados del objeto, y a los que se atribuye o confiere, en el acto, tanto una estructura formal básica predefinida -sobre la que se insertará cada perspectiva particular del objeto- como un campo de significados múltiples, ambos procedentes del horizonte interno. En este acto, cada perspectiva particular del objeto se inserta en la estructura formal suministrada por este horizonte, y que, a modo de esbozo preliminar del objeto imaginario, sirve de armazón sobre el que organizar y conferir unidad a las múltiples perspectivas mostradas por el objeto. En este mismo acto, lo percibido se ve recubierto por un conjunto de significados verbales, reacciones emotivas, puro-sensibles, etc. procedentes de la semiosfera del horizonte interno, contenidos que pasan a formar parte de la estructura noemática anterior.

A su vez, la recepción dialéctica consiste en el proceso mediato y extenso en el tiempo a través del cual interactúan lo puro-sensible y lo lingüístico-conceptual, lo que ocurre de modos diversos: al explicitar, objetivar y tematizar los contenidos aprehendidos en la recepción simbólica, al formular hipótesis acerca de la estructura y sentido del objeto y contrastarlas con la realidad formal de este, o con la proferencia de enunciados que vuelvan inteligible lo visible, todo lo cual orienta las aprehensiones subsiguientes e interviene en la construcción del objeto inmanente de la obra, e incluso en su reconfiguración, como ocurre cuando lo conceptual consigue que lo puro-sensible se nos aparezca de modos nuevos y distintos, sin que, no obstante, quepa nunca reducir a concepto lo percibido.

Según esto, el diálogo con la obra puede entenderse como una exploración consciente y voluntaria del horizonte intencional en busca de materiales relacionados con lo percibido del objeto, de manera que cuando el sujeto reflexiona acerca de lo puro-sensible se desencadena una dinámica de remisiones entre elementos de 
la red cultural en que el empeño por comprender -o bien las asociaciones espontáneas suscitadas por las conexiones entre unidades culturales en el horizonte de recepción- impulsa el movimiento de una unidad a otra o, en su caso -y aquí residiría el potencial de la obra para refigurar la subjetividad, para ampliar el horizonte personal- genera nuevas unidades culturales o nuevas conexiones entre ellas, y se incorporan estos materiales al objeto intencional en ciernes y, por ende, a la subjetividad del receptor.

Al constituirse el objeto inmanente, se resuelven al mismo tiempo las indeterminaciones de la obra por medio de los materiales aportados por el horizonte de constitución. De acuerdo con el modelo propuesto, las percepciones del objeto artístico, por fragmentarias e incompletas que sean, se verán vinculadas, en su recepción, con materiales albergados en ese horizonte, cuya ligadura con lo percibido se establece en virtud de la memoria de experiencias pasadas con objetos en alguna medida afines al objeto presente. Cuando la obra posee un alto grado de indeterminación, los materiales tomados del horizonte de constitución al formarse el objeto imaginario dominan sobre los procedentes de la percepción de la obra, y por tanto el receptor cuenta con un amplio margen de libertad y de iniciativa en su experiencia. Cuando la obra se concibe con una indeterminación mínima, los materiales procedentes del objeto percibido imperan sobre los aportados por el sujeto. Pero, por bajo que sea el grado de negatividad de la obra, esos rasgos formales suscitan siempre todo tipo de asociaciones -conceptuales, sensibles, afectivas...- que se adhieren indefectiblemente al objeto imaginario en ciernes, por lo que no cabe hablar de univocidad de la experiencia artística: esta se ve connotada siempre por la individualidad del receptor.

\section{Las teorías regionales del significado}

El modelo propuesto, pese a su generalidad, permite comprender algunos de los procesos más relevantes que tienen lugar en el encuentro con los objetos artísticos, y, en concreto, el modo en que se resuelven las indeterminaciones de la obra de arte. Aspecto este de la vivencia artística que, al decir de la estética de la recepción, es determinante en la constitución de su sentido. Como se ha intentado mostrar en la primera parte del argumento, la resolución de las indeterminaciones forma parte esencial de la experiencia más allá de la modalidad artística concreta de que se trate o de su grado de mímesis / abstracción, lo que justifica la pertinencia de un modelo que de otro modo cabría tildar de demasiado genérico. En apoyo de una teoría tal, puede decirse que los procesos descritos no son exclusivos de la experiencia estética, 
sino que operan, en mayor o menor medida, en toda experiencia de la realidad. La experiencia estética no se distinguiría de manera radical, pues, de otras formas de vivencia. Su especificidad yace en las cualidades concretas de los objetos imaginarios generados en el encuentro con la obra de arte, en particular en la relevancia existencial de los significados aprehendidos.

Que formas tan diversas de experiencia como las que acontecen ante los distintos tipos de objeto artístico puedan abarcarse desde una teoría única se debe a la base fenomenológica del modelo. Puesto que la fenomenología pretende dar razón de las interacciones entre conciencia y realidad en general, su validez debe mantenerse cuando se aplica al subconjunto de esa realidad formado por los objetos artísticos.

Esta generalidad del modelo propuesto hace de él una especie de matriz teórica que abarque y comprenda aquellas teorías regionales de la experiencia estética que, a modo de perspectivas particulares, se proponen explicar aspectos diversos de esa experiencia. Puesto que el método fenomenológico constituye su objeto de estudio por medio de la integración o síntesis sucesiva de las distintas perspectivas desde las que ese objeto puede ser considerado, las diversas teorías particulares aportarían a ese proceso otros tantos puntos de vista parciales. Así, en el caso de la música, planteamientos tradicionalmente enfrentados y en apariencia incompatibles como son el impresionismo y el formalismo, en un modelo de esta naturaleza no constituyen sino miradas parciales sobre el objeto musical, en cuya vivencia la experiencia óptima de la obra requiere de ambos momentos, y se verá mermada si se prescinde de alguno de ellos. El modelo propuesto engloba ambas perspectivas al dar cuenta de ellas desde las ideas de constitución, de objeto imaginario y de horizonte intencional: el objeto imaginario se construye sobre un esquema básico procedente del sustrato de experiencias previas de otras obras semejantes, y las percepciones puro-sensibles del objeto, obtenidas en su aprehensión "impresionista”, se organizan a través de síntesis sucesivas sobre esa figura básica, y se ven connotadas en el acto de su recepción por múltiples asociaciones, imágenes, reacciones emotivas, etc., que se integran a su vez en ese rizoma que es el objeto imaginario de la obra.

De igual manera, el contraste de este proceso con algunos de los planteamientos teóricos más relevantes acerca del significado musical muestra cómo muchas de estas propuestas pueden "traducirse" de modo más o menos directo en términos fenomenológicos, y de ese modo integrarse en una misma matriz teórica. Así, cuando Enrico Fubini afirma que:

en el curso de su milenaria historia, la música se fue cargando de un buen número de significados extramusicales, tomados prestados, en primer lugar, de los textos poéticos a 
los que aquella acompañaba y, en segundo lugar, de las circunstancias en las que aquella se ejecutaba ${ }^{23}$.

Esto no describe sino el modo en que se sedimentan los significados musicales que forman el horizonte desde el que se recibe la obra. Una perspectiva semiótica como la de Jean Jaques Nattiez en Music and Discourse presenta asimismo importantes paralelos con el planteamiento aquí propuesto: lo que Nattiez denomina dimensión estésica ${ }^{24}$ en la recepción de la pieza musical se corresponde estrechamente con la constitución del objeto imaginario de la obra, en el sentido aquí empleado. Por su parte, la confluencia simultánea de componentes diversos tales como reacciones fisiológicas, emotivas, imaginativas o conceptuales en la experiencia de la obra -como se afirma desde la psicología de la música ${ }^{25}$-, formaría parte de lo que en nuestra propuesta se ha denominado aprehensión simbólica.

Este repaso, aunque claramente superficial, pretende ilustrar el modo en que el modelo da cuenta, en sus propios términos, de muchos de los fenómenos de que se ocupan las distintas teorías particulares del significado en el terreno de la música, aunque lo mismo podría decirse de las referentes a otros territorios del arte. La traducción sistemática de estas propuestas a los conceptos del modelo permitiría ensanchar este a través de las aportaciones particulares de aquéllas, y, por ende, la formación de una matriz teórica común en que las diversas perspectivas se relacionarían entre sí y se complementarían unas a otras.

\section{Conclusiones}

A PARTIR DEL CONCEPTO DE LUGAR DE INDETERMINACión en Roman Ingarden y Wolfgang Iser, se afirma que el vacío es constitutivo de todo objeto artístico, de manera que cualquier forma de arte está integrada por un mixto de negatividad y de un significado más o menos accesible. Esto permite plantear un mecanismo común actuante en la formación del significado/objeto intencional, aplicable tanto para los distintos grados de figuración/abstracción como para las distintas artes. El modelo propuesto se basa en las nociones, de raíz fenomenológica, de objeto imaginario o estructura noemática, de constitución de ese objeto, y de horizonte intencional en cuyo seno tiene lugar su constitución. Tanto el horizonte intencional como el

\footnotetext{
${ }^{23}$ Fubini, E., Música y lenguaje en la estética contemporánea, op. cit., p. 72.

${ }^{24}$ Cf. Nattiez, Jean-Jacques, (1990). Music and discourse. Towards a Semiology of Music, Princeton, Princeton University Press, 1990, p. 12.

25 Juslin, P., "Emotional Responses to Music", passim.
} 
objeto inmanente se organizarían a modo de rizoma integrado por contenidos heterogéneos interrelacionados. La formación del objeto inmanente se entendería como un ensamblaje sintético de contenidos heterogéneos procedentes de la percepción del objeto, del horizonte interno y de la actividad reflexiva del receptor en el curso de la experiencia estética. Este modelo pretende funcionar a modo de matriz que dé cabida y relacione entre sí las distintas teorías particulares acerca del significado de la obra de arte. El esbozo aquí ensayado de contraste con una muestra de estas teorías parece confirmar la verosimilitud del planteamiento. 


\section{Referencias Bibliográficas}

Fubini, Enrico. Música y lenguaje en la estética contemporánea, Madrid, Alianza, 2006.

Gurwitsch, Aron, El campo de la conciencia. Un análisis fenomenológico, Madrid, Alianza, 1979.

Ingarden, R., "Concreción y reconstrucción”. en Warning, Rainer (ed.), Estética de la recepción, madrid: la Balsa de Medusa, 1989, pp. 35-53.

Iser, Wolfgang, El acto de leer. Teoría del efecto estético, Madrid, Taurus, 1987.

Jauss, Hans-Robert, Experiencia estética y hermenéutica literaria. Ensayos en el campo de la experiencia estética, Madrid, Taurus, 1986.

Juslin, P., "Emotional Responses to Music". En Hallam, Susan, Cross, Ian, y Thaut, Michael (eds.), Oxford Handbook of Music Psychology. Oxford: Oxford University Press, 2012, pp. 131-141.

Kandinsky, Wassily, Punto y línea sobre el plano. Contribución al análisis de los elementos pictóricos, Barcelona, Labor, 1991.

Nattiez, Jean Jacques, Music and discourse. Towards a Semiology of Music, Princeton, Princeton University Press, 1990.

Navarro, Rosa, Cómo leer un poema, Barcelona, Ariel, 1998.

Oteiza, J., "El final del arte contemporáneo". En Oteiza. Propósito experimental, Madrid: Fundación caja de pensiones, 1989, p. 230.

Pérez, Alfonso E., Pintura barroca en españa (1600-1750), Madrid, cátedra, 1992.

Tarasti, Eero, Sémiotique musicale, Limoges, PULIM, 1996.

DOI: http://doi.org/10.15366/bp2019.22.018

Bajo Palabra. II Época. No 22. Pgs: 347-362 